\title{
Non-Destructive Quality Inspection of Potato Tubers Using Automated Vision System
}

\author{
Ayman Ibrahim $^{\mathrm{a}, 1}$, Nazeer El-Bialee ${ }^{\mathrm{a}, 2}$, Mohsen Saad $^{\mathrm{b}}$, Elio Romano $^{\mathrm{c}}$ \\ ${ }^{a}$ Agricultural Engineering Research Institute (AEnRI), Agricultural Research Center (ARC), Egypt \\ E-mail: ' aymanelgizawee@gmail.com; ${ }^{2}$ phdzizo1@gmail.com \\ ${ }^{b}$ Horticultural Research Institute, Agricultural Research Center (ARC), Egypt \\ E-mail: monsenyoukasha@yahoo.com \\ ${ }^{c}$ CREA (Council for Agricultural Research and Economics) of Treviglio (BG), Italy \\ E-mail: elio.romano@crea.gov.it
}

\begin{abstract}
In this investigation, an automated vision system "AVS" for non-destructive quality inspection of potato tubers "PT" was developed. Color, size, mass, firmness, and the texture homogeneity of the "PT" surface, various sensitive features were studied, and extracted from the digital image by using the R program. Otsu threshold method, RGB, Lu*v*, CIE $\mathrm{LCh}_{\mathrm{uv}}$ color models, and texture analysis by using the package Gray-Level Co-Occurrence Matrices (GLCMs) were applied. The results showed a great correlation between the tuber pixel area percentages $(D I M=$ dimension as a percentage of total pixels), and both mass and geometric mean diameter (GMD) of all "PT" varieties. The color results demonstrated that the hue angle $\left(h_{u v}\right)$ ranged from 68.92 to $96.61^{\circ}$, and the "PT" color was classified into deep and light color intensity. The "AVS" could predict the mass and size, and gave statistical data at the mass production level, in terms of the inspecting samples No., mass, and grades based on size, color, and free from injuries through the texture homogeneity of tuber surface. A predictive model hypothesized based on the tuber's surface texture characteristics for predicting the tubers firmness was statistically significant. This "AVS" can be applied as a non-destructive, precise, and symmetric technique in-line inspection, the quality of "PT", also helping decision-makers in the agricultural field and stakeholders to improve the horticulture sector through the statistical data issued by this system.
\end{abstract}

Keywords - potato tuber; quality inspection; image processing; automated vision systems; color analysis; texture features.

\section{INTRODUCTION}

Agriculture is a major industry in Egypt, including production, processing, transportation, and support services. Considering the large population grows day after day, increasing agricultural production has become an urgent necessity to meet their food needs. Egypt is Africa's largest potato producer and ranks 14th in the world in terms of ware potato production. The production amount of the "PT" crop is $5.3 \mathrm{Tg}$ and is continually increasing annually to meet the needs of overpopulation [1], [2]. Hence, the challenge arises in applying modern technology in increasing agricultural production and quality inspection of agricultural products. Fresh horticultural commodity's quality is a combination of external and internal characteristics that give more acceptability to commodity value.

Consumers judge the fresh fruits and vegetables "F \& V" quality based on appearance and quality characteristics at the purchase time. Quality characteristics of "F \& V" include appearance, texture, flavor, nutrition, and free of blemishes (safe). Appearance attributes involved color, shape, and crucial geometric properties, i.e., fruit dimensions, geometric mean diameter "GMD", and size. Meanwhile, to create sizing systems, the physical attributes, i.e., volume, mass, density, and surface areas, are essential [3]. Therefore, the appearance has a significant impact on market prices and consumer. Besides, it significantly affects transportation options and storage methods [4], [5].

Traditional quality inspection methods, i.e., manual sorting and grading processes based on human labor, became slow, tedious, time-consuming, non-consistent, and full of many mistakes. Also, because of these methods' continued use, a great loss in data and statistics on agricultural product quality occurred, reducing the marketing and export value of Egyptian crops that leads to lower national income [6].

On the other hand, conventional methods used to inspect agricultural products quality depend on human inspection according to their physiological maturity by eye trained in 
determining color, size, and free of defects, also detect hardness or firmness by hand touch [7]-[9]. Thus, there are a lot of instruments such as Magness-Taylor (MT) firmness test, Brix refractometer for soluble solids content, colorimeter to measure color, and High-performance liquid chromatography (HPLC) instrument to estimate chemical compounds. These techniques are destructive and only can test a few samples, and they are not suitable for sorting and grading each sample of "F\&V". Therefore, a suitable solution over the years is non-destructive methods. Among the many types of non-destructive sensing techniques, optical techniques are instrumental because they are rapid, non-destructive, cost-effective, and generally safe to use. By the acceleration of the growth and development in machine vision system "MVS" technology, it has become possible to overwhelm these limits precisely and non-destructively based on machine vision systems for fresh "F\&V" quality detection [10].

Furthermore, fresh "F\&V" quality inspection based on "MVS" by computer has gained an excellent reputation compared to her counterpart that depends on human labor at furthermost packinghouses in the developed countries [11]. "MVS" dependent on computers and programs based on image processing and analyzing data, provide precision in performance, speed, high productivity, statistics in addition to low cost. As many researchers mentioned that, as a result, in recent advances in computer technology, automation, and control a lot of manufacturers have revolved their care to "MVS" inspection as particular in quality inspection of agricultural products [12]. Most automated machine vision systems "AMVS" for agricultural products inspection quality, depend on their theory of work, on taking the object image or more to be inspected, then, image processed and analyzed to determine the object quality [13]. Computer vision systems "CVS" in "F\&V" sorting mainly focus on some quality features, i.e., color, size, shape and presence, external defects of the fruit [14]. The RGB, HSI, and CIELab color models are usually used for color inspection of "F\&V" quality. Lab color space is frequently less affected by the camera sensor variants compared to the RGB color model [15]. An image-processing "IP" algorithm for extracting shape, size, and color features for sorting tomatoes accordingly [15]. "AMVS" has been developed for the potatoes shape classification [16].

Moreover, "MVS" is used based on "IP" techniques to inspect and measure the date fruits and potato quality according to some quality attributes i.e., color and size [13][17]. Texture features are also referred to as second-order features because they capture the gray values, spatial that contribute to the texture perception, by representing the properties of pixels in pairs [18]. Texture property is representing the surface and the image object structure [19]. A gray-level co-occurrence matrix algorithm (GLCM) is a tabulation of pixel brightness values (gray levels) that occur in an image and describes the image texture, which is an examining texture statistical method, that considers the relationship of the spatial pixel [20], [21]. Where, different features, i.e., correlation, angular second moment, contrast, entropy, etc., can describe the textured surface and are enough to find a respectable relation between image texture and food properties [22]. Therefore, it is confirmed that the combination of both color and texture features increased the accurateness in all the grading classes in the "IP" features evaluation [23]. An "MVS" has been developed for grading dried figs and the results showed that there was enhanced sorting accuracy for all the classes up to $95.2 \%$ and the system mean rate $\approx$ of $90 \mathrm{kgh}-1$ for the grading process [24]. Carrot grading using "MV" system and the results showed that the constructed image acquisition system "IAS" success to extract the feature parameters of the carrot accurately [25].

As a simple and easy to solve algorithm, the extreme learning machine (ELM) model based on shape and color parameters has the best recognition effect and the accuracy reaches $96.67 \%$. Applied computer vision system "CVS" and machine learning algorithms "MLA" aims to obtain a prediction model for cherry tomato volume and mass estimation [12]. The results showed that the prediction model's accuracy was 0.971 and 0.969 in mass and volume. Hence, it concluded that the system as a non-destructive technique can be applied in both on and/or inline postharvest processing of cherry tomatoes for automatic sorting and grading procedures. Likewise, an "MVS" has been developed to detect irregular potatoes in real-time, and the experiments showed that the success of an in-line "MVS" was $96.2 \%$ [26]. As well as, the well-shaped potatoes were classified by size, reaching $100 \%$,, accuracy. By the same token, an algorithm-based "IP" technique has been developed for detecting in-line "PT"s "PT", and the results showed that 100 and $97 \%$, of the contact points between the tubers and the clods were found successfully [27]. Therefore, it concluded that the algorithm can be applied to the packing houses to replace the traditional method. From this perspective and considering strengthen the competitiveness of Egyptian agricultural exports. This study's main objectives are to develop an "AVS" to inspect the "PT" quality and provide a digital database depends on color, size, mass, and external injuries percentage.

\section{MATERIALS AND METHODS}

\section{A. Experiment Setup and Data Collection}

Experiments of this study were conducted between February 2019 and May 2020 at the Agricultural Engineering Research Institute (AEnRI), Horticultural Research Institute, Agricultural Research Center (ARC), Egypt, and CREA (Council for Agricultural Research and Economics) of Treviglio (BG), Italy. Spunta, Alpha, and Burn, various varieties of "PT"s were used. From one of the domestic markets, 100 tubers/variety were selected at the ripe stage, differ in shape, mass, and size. Subsequently, tubers were washed, dried with a paper towel, and labeled with a number. Some physical characteristics of "PT" samples were measured, for use in developing the automated vision system based on "IP" and analysis, for inspection quality of "PT" and prediction of some quality attributes. Digital vernier caliper measured length, width, and the thickness of each tuber with an accuracy of $0.01 \mathrm{~mm}$, geometric mean diameter (GMD) was calculated [28]. The mass was recorded by electronic digital balance having a sensitivity of $0.01 \mathrm{~g}$. Finally, the firmness of each "PT" was measured by fruit hardness tester (model FR-5120) with penetrometer tip $11 \mathrm{~mm}$, and the "PT" firmness values 
expressed kgf. The image capture system is composed of a black lighting chamber painted, equipped with a machine vision camera (Model SXY-I30 equipped with lens 2/3" Mega-Pixel) in a vertical position always at the same height equal to $40 \mathrm{~cm}$ above the tuber. The lighting source was always identical, it consisted of two parallel lamps (Natural Daylight, 20W/965, Toshiba, D65, standard light source) each lamp contains two fluorescent tubes installed at an angle $\left(45^{\circ}\right)$ and $35 \mathrm{~cm}$ height above the tuber. The camera was connected via Intel core i5-3320M, $3.30 \mathrm{GHz}, 8 \mathrm{~GB}$ physical memory (Intel® HD Graphics 4000), Microsoft Windows 10. The tubers were photographed with a resolution of 480,000 pixels, two images were taken for each tuber for subsequent analysis.

\section{B. Image Processing Code}

The images were processed, using $\mathrm{R}$ software (Comprehensive $\mathrm{R}$ Archive Network-CRAN), of the Institute for Statistics and Mathematics in Wien-Umgebung,
Austria [29]. By applying the Otsu threshold method after conversion to grayscale, to binarize the image and count the percentage of the white pixels belonging to the tuber compared to those of the entire photograph that represented the tuber with the black background. Otsu's thresholding method is useful to perform clustering-based image thresholding automatically. The algorithm assumes that image pixel intensities' distribution follows a bi-modal histogram and separates those pixels into two classes (e.g., foreground and background). The optimal threshold value is determined by minimizing the combined intra-class variance. The threshold value was calculated for each image frame separately, resulting in an output vector of length equal to the image's total number of frames. Therefore, the percentage incidence of the pixels (DIM=dimension as a percentage of total pixels) attributed to the tuber concerning the total number of pixels was calculated as shown in Fig. 1.

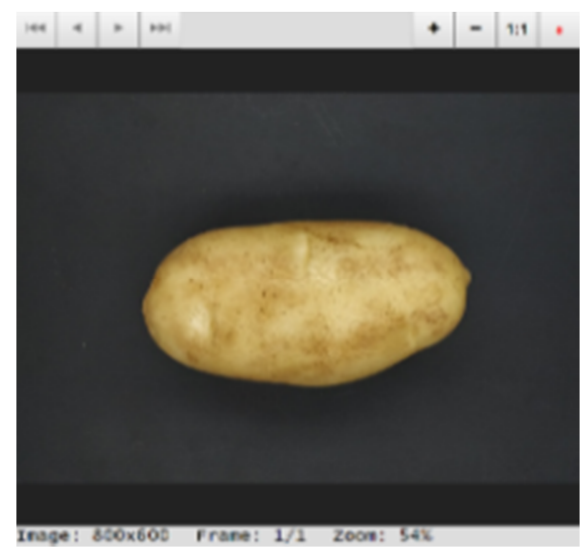

(a) Original Image

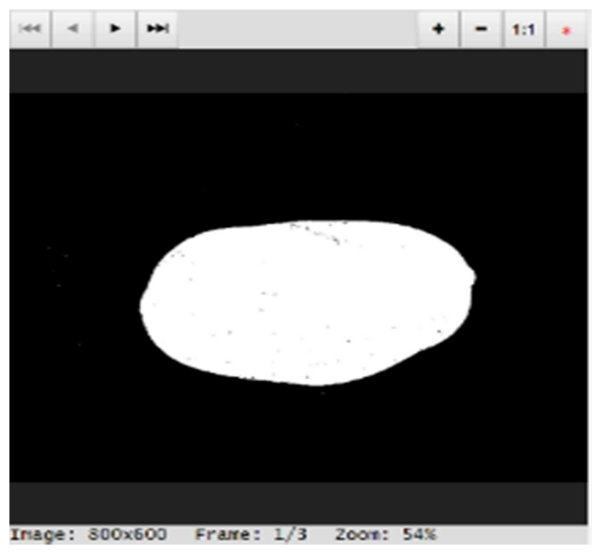

(b) Binary Image

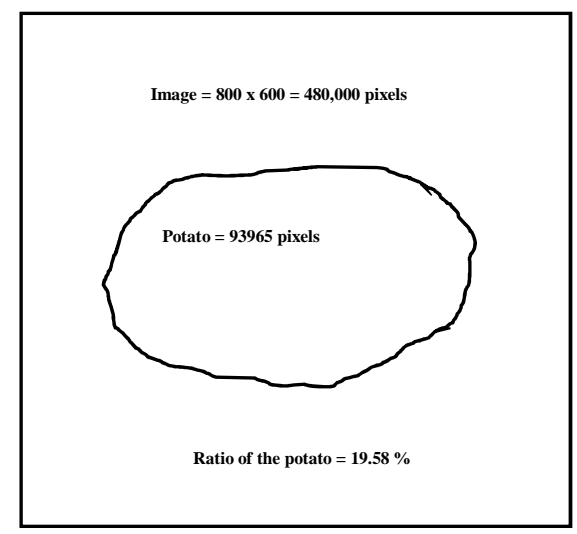

(c) DIM

Fig. 1 Depicts the image segmentation process and marks the region of interest (ROI).

Color analysis and color feature extraction, a median filter was used to remove noise from images. Subsequently, a central surface was identified for all the tubers, in which three-color samples were performed. The images were analyzed by separating their three layers dedicated to the RGB channels. So, for each pixel observed, the corresponding value was read in layer $\mathrm{R}, \mathrm{G}$, and $\mathrm{B}$. Subsequently, the values were converted to CIELUV model [30] through the grDevices $\mathrm{R}$ package, which defined by the three $\mathrm{L}, \mathrm{u}^{*}$ and $\mathrm{v}^{*}$ coordinates, where $\mathrm{C}_{\mathrm{uv}}$ is the chroma and $\mathrm{h}_{\mathrm{uv}}$ is the hue:

$$
\begin{gathered}
C_{u v}^{*}=\sqrt{\left(u^{*}\right)^{2}+\left(v^{*}\right)^{2}} \\
\text { huv }=\operatorname{atan} 2\left(\mathrm{v}^{*}, \mathrm{u}^{*}\right)
\end{gathered}
$$

Where, atan 2 function, a "two-argument arctangent", computes the polar angle from a Cartesian coordinate pair.

Texture analysis of "PT" is determined through the package Gray-Level Co-Occurrence Matrices (GLCMs) algorithm [20-31]. The texture calculation is coded in $\mathrm{C}++$ to optimize computation time. The GLCM function of the software $\mathrm{R}$ was therefore applied to the loaded raster's, which allowed to obtain a RasterStack, which is an object containing six calculated layers; Mean (the average value of the gray level), dissimilarity (dissimilarity between the grays), contrast (the contrast between the levels), entropy (the entropy of the distribution of the gray levels), homogeneity (the gray homogeneity), and the second moment (gray distribution ratio) as shown in Fig. 2.

\section{Statistical analysis}

Minimum, maximum values, averages, standard deviations, and coefficient of variation were counted with the Excel program. Data relating to the color and uniformity information of the "PT" images were processed [29], through the basic packages, and in addition to the Agricola package. The mean and standard deviations $(\sigma)$ were calculated and after the verification of the conditions of normal data distribution (Shapiro-Wilk test) and homogeneity of the variances (Bartlett test) the analysis of variances was developed (ANOVA), considering varieties and samples as factors. Pearson linear correlations between the observed factors were also investigated. 

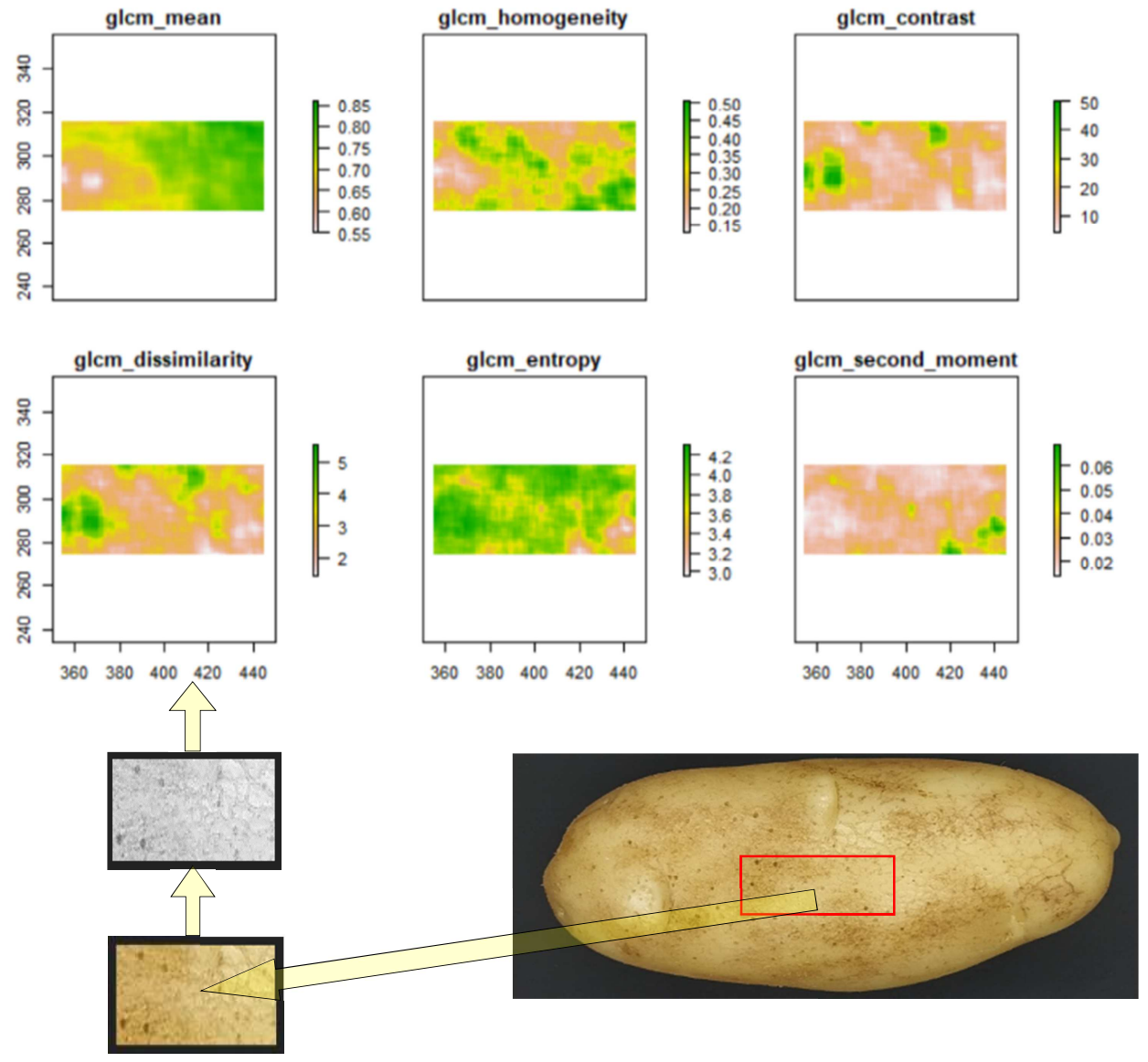

Fig. 2 Describe the processing of GLCM and extract distinctive texture features of potato

\section{RESULTS AND DISCUSSION}

Some physical characteristics of "PT" samples under study were described by measuring each of length, width, thickness, mass, and firmness, to develop an automated vision system "AVS" to inspect the quality of "PT" non- destructively. Furthermore, the geometric mean diameter (GMD) for each tuber was calculated. Both mass and "GMD" estimation results for "PT" data are sketched in Fig. 3 , which demonstrates the wide range of differences in mass and size between diverse "PT".

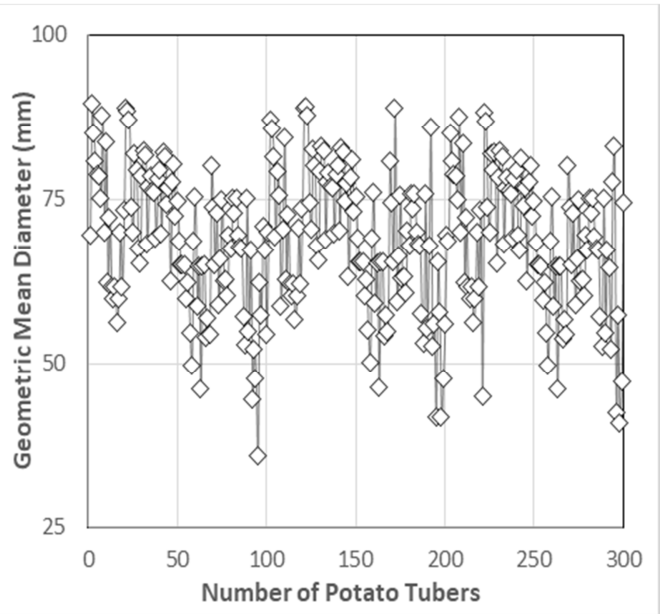

Fig. 3 The mass and GMD estimations of "PT".

Similarly, the statistics "PT" data of length, width, thickness, GMD, mass, and firmness are listed in Table I. Evidently, there are no substantial differences between the Alpha and Burn potato varieties. In contrast, the Spunta variety recorded the highest average values of 85.94 $\mathrm{mm}, 71.91 \mathrm{~mm}$, and $235.75 \mathrm{~g}$ for length, width, and mass, respectively, followed by Burn and Alpha varieties. On the contrary, the highest average value of firmness was 6.44 for the Alpha variety while the lowest average value of firmness was 5.33 (Kgf) for the Spunta variety. 
TABLE I

SOME PHYSICAL CHARACTERISTICS FOR SOME VARIETIES OF "PT"

\begin{tabular}{|c|c|c|c|c|c|c|}
\hline \multicolumn{2}{|c|}{$\begin{array}{c}\text { Physical } \\
\text { characteristics }\end{array}$} & Max. & Min. & Avg. & SD & $\mathrm{CV}$ \\
\hline \multirow{6}{*}{$\frac{a}{2}$} & $\mathrm{~L}(\mathrm{~mm})$ & 120.20 & 50.00 & 91.56 & 17.91 & 0.20 \\
\hline & $\mathrm{W}(\mathrm{mm})$ & 70.70 & 30.80 & 57.22 & 9.73 & 0.17 \\
\hline & $\mathrm{T}(\mathrm{mm})$ & 60.10 & 30.09 & 44.99 & 7.37 & 0.16 \\
\hline & GMD (mm) & 75.29 & 35.92 & 61.66 & 10.32 & 0.17 \\
\hline & Mass (g) & 290.67 & 35.19 & 178.41 & 71.91 & 0.40 \\
\hline & Firmness & 8.05 & 5.20 & 6.44 & 0.65 & 0.10 \\
\hline \multirow{6}{*}{ 志 } & $\mathrm{L}(\mathrm{mm})$ & 120.90 & 60.10 & 86.89 & 15.18 & 0.17 \\
\hline & $\mathrm{W}(\mathrm{mm})$ & 76.60 & 40.50 & 60.30 & 8.29 & 0.14 \\
\hline & $\mathrm{T}(\mathrm{mm})$ & 60.30 & 40.00 & 49.72 & 5.47 & 0.11 \\
\hline & GMD $(\mathrm{mm})$ & 80.13 & 46.04 & 63.71 & 7.95 & 0.12 \\
\hline & Mass (g) & 363.04 & 62.19 & 180.24 & 69.58 & 0.39 \\
\hline & Firmness & 7.41 & 5.43 & 6.29 & 0.55 & 0.09 \\
\hline \multirow{6}{*}{ 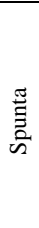 } & $\mathrm{L}(\mathrm{mm})$ & 164.50 & 69.60 & 107.28 & 21.17 & 0.20 \\
\hline & $\mathrm{W}(\mathrm{mm})$ & 82.33 & 51.70 & 64.59 & 8.06 & 0.12 \\
\hline & $\mathrm{T}(\mathrm{mm})$ & 76.50 & 39.95 & 54.42 & 10.79 & 0.20 \\
\hline & GMD (mm) & 89.68 & 56.29 & 71.91 & 10.32 & 0.14 \\
\hline & Mass (g) & 414.66 & 111.69 & 235.75 & 97.78 & 0.41 \\
\hline & Firmness & 6.42 & 4.20 & 5.33 & 0.70 & 0.13 \\
\hline
\end{tabular}

Max. (Maximum value), Min. (Minimum value), Avg. (Average), SD (standard deviation), CV (coefficient of variation), L. (length), W. (width), T. (thickness), GMD (geometric mean diameter).

\section{A. Vision system}

The "AVS" for non-destructive quality inspection of "PT" in this study uses the calibration method to detect the actual size and "PT" mass. A pixel is a measuring unit of digital image and to calibrate the number of pixels to actual size by $\mathrm{mm}$ and actual mass by g. Therefore, it was necessary to measure all data about size represented in GMD and mass for each "PT" to establish a precision calibration system to predict size and mass, and classify these tubers based on size and mass into more than one category. After completing the segmentation process of the image and determining the region of interest (ROI) in the image "PT", all white pixels representing the "PT" were counted and then the percentage was taken according to the total area of the image, the results are recorded in Table II.

TABLE II

Some Statistical Properties of Tuber Pixels Percentages

\begin{tabular}{|c|c|c|c|}
\hline \multicolumn{4}{|c|}{ Potato Varieties } \\
\hline Statistical properties & Alpha & Burn & Spunta \\
\cline { 2 - 4 } & Pixels (\%) & Pixels (\%) & Pixels (\%) \\
\hline Max. & 23.15 & 27.94 & 28.14 \\
\hline Min. & 4.66 & 6.34 & 8.84 \\
\hline Avg. & 15.60 & 15.27 & 15.8 \\
\hline SD & 5.01 & 4.39 & 5.14 \\
\hline CV & 0.32 & 0.32 & 0.33 \\
\hline \multicolumn{4}{|l}{} \\
\hline
\end{tabular}

The incidence percentages of the tuber pixels (DIM=dimension as a percentage of total pixels), showed that the percentage of the average pixels of potato varieties was 15.60, 15.27, and 15.8\%., for Alpha, Burn, and Spunta, respectively. While within each variety there was a considerable variability about the tuber size. Where, the pixel percentage (Pixels \%) range, was $4.66-23.15 \%$ with "SD" $\approx 5.01$ for Alpha. As well as Burn was between 6.34 and $27.94 \%$, with an "SD" equal to 4.39 . While the tuber pixels range for Spunta, were 8.84 to $28.14 \%$., with "SD" $\approx$ 5.14. Furthermore, obtained results clearly show that there was a positive linear correlation between the pixels percentage of tubers and both mass and GMD for all potato varieties as shown in Fig. 4.
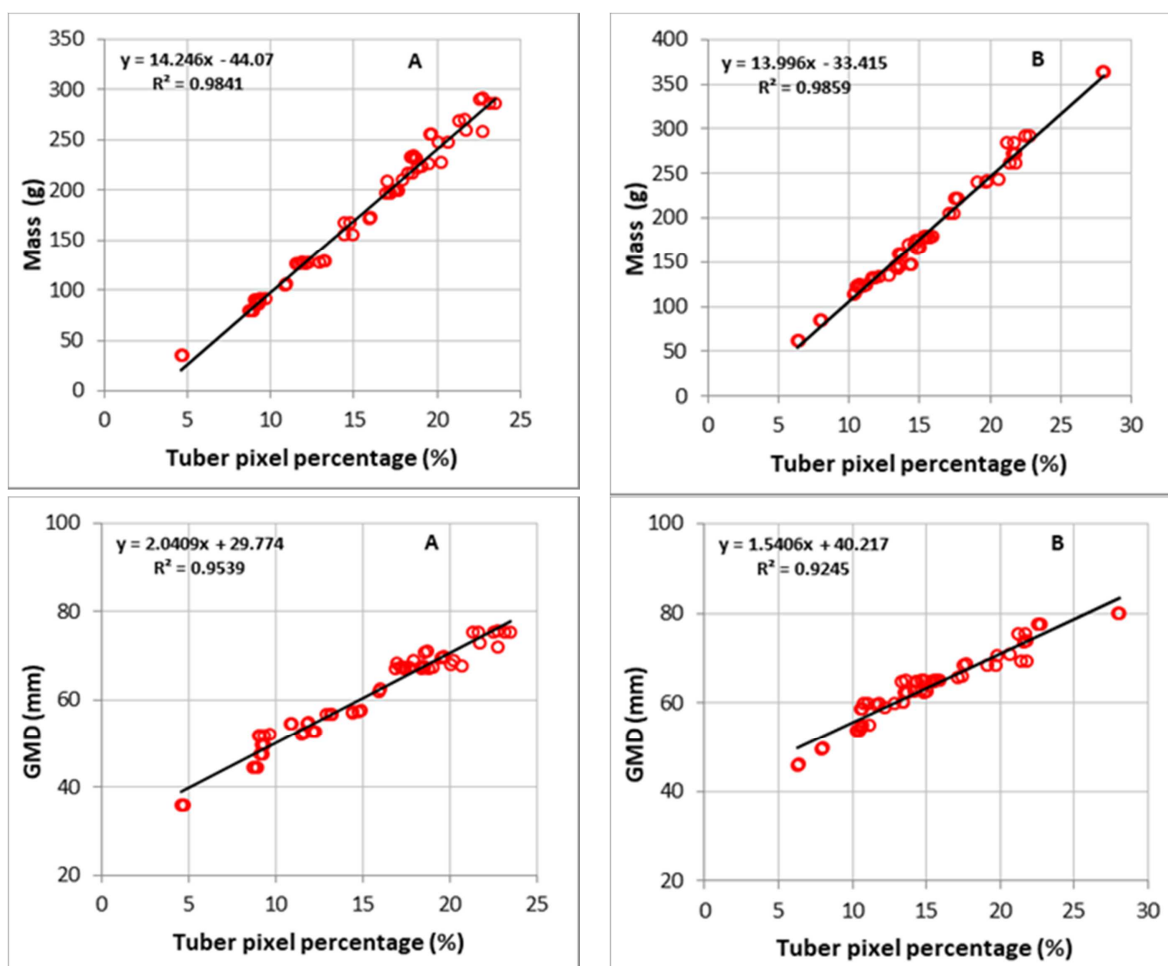

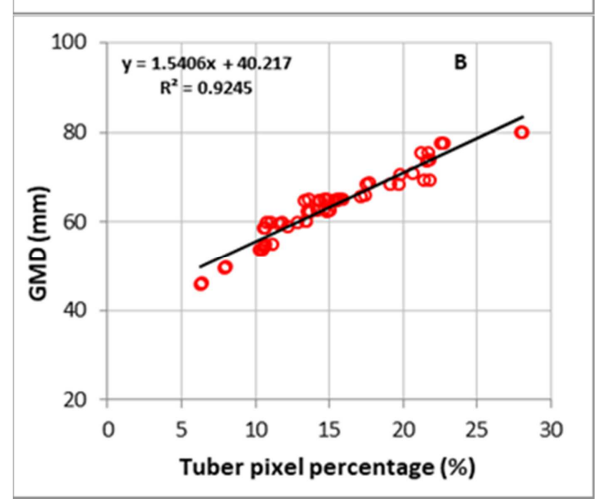

Fig. 4 Correlation between the values of pixels percentage and both mass and GMD for Alpha (A), Burn (B), and Spunta (S). 
Rather, mass $=14.25$ (Pixels \%) -44.07 with $\mathrm{R}=0.98,=$ 14 (Pixels \%) - 33.42 with $\mathrm{R}=0.99$, and $=17.45$ (Pixels \%) - 41.66 with $\mathrm{R}=0.95$ for Alpha, Burn, and Spunta varieties, respectively. Meanwhile, GMD $=2.04($ Pixels \%) +29.77 with $\mathrm{R}=0.95,=1.54$ (Pixels $\%)+40.22$ with $\mathrm{R}=0.93$, and $=1.85($ Pixels \%) +42.27 with $\mathrm{R}=0.92$ for Alpha, Burn, and Spunta varieties, respectively. Given, mass, GMD, and the current wide range of "PT" as pixels (\%) that ranged from 4.66 to $28.14 \%$ as mentioned in Table II, the "PT" were classified into five categories according to these ranges as tabulated in Table III.

TABLE III

SIZING CATEGORIES OF "PT" ACCORDING TO MASS, GMD, AND DIM

\begin{tabular}{|l|c|c|c|c|}
\hline \multicolumn{2}{|c|}{ N. Categories } & Mass (g) & GMD $(\mathrm{mm})$ & DIM Pixels $(\%)$ \\
\hline I. & Jumbo & I $\geq 350$ & I $\geq 80$ & I $\geq 25$ \\
\hline II. & Big & $250 \leq$ II $<350$ & $69 \leq$ II $<80$ & $19.5 \leq$ II $<25$ \\
\hline III. & Medium & $\begin{array}{c}150 \leq \text { III }< \\
250\end{array}$ & $57 \leq$ III $<69$ & $13.5 \leq$ III $<19.5$ \\
\hline IV. & Small & $50 \leq$ IV $<150$ & $43 \leq$ IV $<57$ & $6 \leq$ IV $<13.5$ \\
\hline V. & Very Small & V $<50$ & V $<43$ & V $<6$ \\
\hline
\end{tabular}

GMD (geometric mean diameter) and DIM (dimension as a percentage of total pixels)

The verification test of the automated vision grading system for "PT" according to mass and GMD was conducted, then, the performance, accuracy, and results of the proposed grading vision system are listed in Table IV. The results show that the differences between measured and predicted mass ranged from 0.91 to $16.53(\mathrm{~g})$ with a mean error ratio of $4.59 \%$, while the ranged of the difference's values between measured and predicted GMD were 0.56 to 5.71 $\mathrm{mm}$, with a mean error ratio $3.04 \%$. These results show the high accuracy of the potato automated vision grading system according to mass and GMD.

\section{TABLE IV}

The VerificAtion of the ACCURACY OF GRADING "AVS" FOR "PT" ACCORDING TO MASS AND GMD PARAMETERS

\begin{tabular}{|c|c|c|c|c|c|c|c|c|}
\hline \multirow{2}{*}{$\begin{array}{l}\dot{0} \\
\frac{0}{z} \\
\frac{\tilde{Z}}{\tilde{E}} \\
\tilde{n}\end{array}$} & \multicolumn{4}{|c|}{ Mass (g) } & \multicolumn{4}{|c|}{ GMD (mm) } \\
\hline & 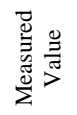 & 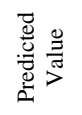 & 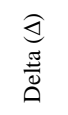 & 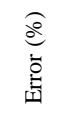 & 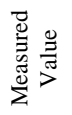 & 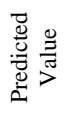 & 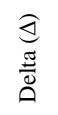 & $\frac{\widehat{c}}{\stackrel{0}{0}}$ \\
\hline 1 & 258.84 & 268.44 & 9.60 & 3.71 & 72.98 & 76.09 & 3.11 & 4.26 \\
\hline 2 & 155.73 & 164.63 & 8.90 & 5.72 & 57.12 & 62.83 & 5.71 & 10.00 \\
\hline 3 & 199.22 & 207.67 & 8.45 & 4.24 & 67.35 & 68.33 & 0.98 & 1.46 \\
\hline 4 & 209.18 & 214.03 & 4.85 & 2.32 & 68.22 & 69.14 & 0.92 & 1.35 \\
\hline 5 & 89.74 & 88.83 & 0.91 & 1.01 & 51.98 & 53.15 & 1.17 & 2.25 \\
\hline 6 & 85.1 & 73.46 & 11.64 & 13.68 & 49.80 & 51.19 & 1.39 & 2.79 \\
\hline 7 & 284.25 & 267.72 & 16.53 & 5.82 & 75.43 & 75.99 & 0.56 & 0.74 \\
\hline 8 & 114.41 & 108.41 & 6.00 & 5.24 & 53.89 & 55.65 & 1.76 & 3.27 \\
\hline 9 & 272.08 & 266.98 & 5.10 & 1.87 & 73.87 & 75.90 & 2.03 & 2.75 \\
\hline 10 & 166.87 & 170.61 & 3.74 & 2.24 & 62.62 & 63.6 & 0.98 & 1.56 \\
\hline Avg. & & & & 4.59 & & & & 3.04 \\
\hline
\end{tabular}

Delta $(\Delta)$ Difference between predicted and measured values

\section{B. Color analysis}

Color analysis of "PT", performed by RGB, Lu*v* and $\mathrm{CIE} \mathrm{LCh}_{\mathrm{uv}}$, color models and statistical details (e.g., Min., Max., Avg, SD, and CV), were presented in Table V.

TABLE V

The COlOR VAlues of "PT", PERFORMEd By RGB, LU*V* AND CIE LCHuV COLOR MOdELS

\begin{tabular}{|c|c|c|c|c|c|c|c|c|c|}
\hline \multicolumn{2}{|c|}{ Parameters } & $\mathrm{R}$ & $\mathrm{G}$ & $\mathrm{B}$ & $\mathrm{L}$ & $\mathrm{u}^{*}$ & $\mathrm{~V}^{*}$ & $\mathrm{~h}_{\mathrm{uv}}$ & $\mathrm{C}_{\mathrm{uv}}$ \\
\hline \multirow{5}{*}{$\frac{\frac{\pi}{2}}{\frac{\pi}{2}}$} & Max. & 255.00 & 230.00 & 174.00 & 91.66 & 8.42 & 53.87 & 92.97 & 54.08 \\
\hline & Min. & 163.00 & 133.00 & 47.00 & 56.88 & -1.73 & 28.57 & 80.13 & 28.57 \\
\hline & Avg. & 219.29 & 188.18 & 115.18 & 77.46 & 2.04 & 41.10 & 87.50 & 41.21 \\
\hline & SD & 13.04 & 14.81 & 18.34 & 5.22 & 1.38 & 3.91 & 1.76 & 3.95 \\
\hline & $\mathrm{CV}$ & 0.06 & 0.08 & 0.16 & 0.07 & 0.68 & 0.10 & 0.02 & 0.10 \\
\hline \multirow{5}{*}{$\underset{\Xi}{\Xi}$} & Max. & 255.00 & 238.00 & 166.00 & 93.97 & 9.63 & 57.57 & 96.61 & 57.66 \\
\hline & Min. & 138.00 & 106.00 & 33.00 & 46.78 & -4.31 & 36.99 & 78.26 & 37.24 \\
\hline & Avg. & 219.64 & 185.71 & 99.30 & 76.56 & 2.27 & 47.68 & 87.49 & 47.81 \\
\hline & SD & 14.94 & 16.27 & 16.53 & 5.70 & 1.80 & 3.52 & 2.31 & 3.47 \\
\hline & $\mathrm{CV}$ & 0.07 & 0.09 & 0.17 & 0.07 & 0.80 & 0.07 & 0.03 & 0.07 \\
\hline \multirow{5}{*}{$\begin{array}{l}\stackrel{\Xi}{\Xi} \\
\text { ڤ̆ } \\
\text { ڤn }\end{array}$} & Max. & 255.00 & 255.00 & 180.00 & 98.47 & 20.93 & 63.21 & 96.10 & 64.48 \\
\hline & Min. & 176.00 & 115.00 & 52.00 & 51.77 & -6.05 & 34.56 & 68.92 & 35.16 \\
\hline & Avg. & 237.59 & 193.67 & 104.22 & 80.43 & 6.40 & 50.10 & 83.06 & 50.85 \\
\hline & SD & 21.53 & 32.10 & 28.29 & 10.46 & 6.49 & 7.97 & 6.66 & 8.32 \\
\hline & $\mathrm{CV}$ & 0.09 & 0.17 & 0.27 & 0.13 & 1.01 & 0.16 & 0.08 & 0.16 \\
\hline
\end{tabular}

R. (Red), G (Green), B (Blue), L (Lightness), $u^{*} \& v^{*}$ (chromaticity coordinates), $\mathrm{h}_{\mathrm{uv}}$ (hue angle), $\mathrm{C}_{\mathrm{uv}}$ (chroma)

The highest average values of $\mathrm{R}$ were $237.59 \pm 21.53$ for Spunta, followed by Alpha and Burn varieties almost the same value around 219. Thus, the highest average values of G, were reported by Spunta then Alpha and Burn varieties. While, the highest average values of $B$ were notified at the Alpha variety followed by Spunta and Burn, respectively, this large range of differences in RGB values is shown in Fig. 5(A). As regards to the colorimetric coordinates of the $\mathrm{Lu}^{*} \mathrm{v}^{*}$ color model, Alpha variety recorded an average value of $\mathrm{L}=77.46 \pm 5.22, \mathrm{u}^{*}=2.04 \pm 1.38$, and $\mathrm{v}^{*}=41.10 \pm 3.91$; Burn variety $\mathrm{L}=76.56 \pm 5.70, \mathrm{u}^{*}=2.27 \pm 1.80$ and $\mathrm{v}^{*}=$ $47.68 \pm 3.52$, also Spunta $L=80.43 \pm 10.46, u^{*}=6.40 \pm$ 6.49 and $\mathrm{v}^{*}=50.10 \pm 7.97$. Meanwhile, it was also noted

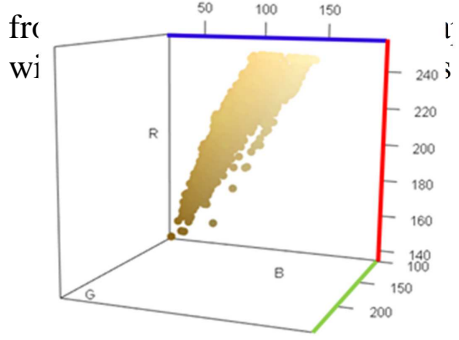

A

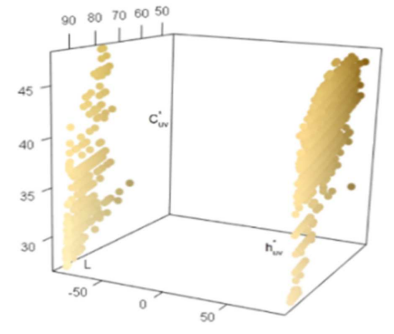

Fig. 5 Three-dimensional graphs depicted the wide range of RGB (A) and $\mathrm{LCh}_{\mathrm{uv}}(\mathrm{B})$ color models.

Where the average values of the $\mathrm{CIE} \mathrm{LCh}_{\mathrm{uv}}$ color model were as follows, the averages of hue angle $\left(\mathrm{h}_{\mathrm{uv}}\right)$ were $87.50 \pm$ 
1.76, 87.49 \pm 2.31 , and 83.06 \pm 6.66 for Alpha, Burn, and Spunta varieties, respectively. Similarly, the average values of chroma $\left(\mathrm{C}_{\mathrm{uv}}\right) 41.21 \pm 3.95,47.81 \pm 3.47$, and $50.85 \pm 8.32$ for Alpha, Burn, and Spunta varieties, respectively. Through the color range of the hue angle $\left(\mathrm{h}_{\mathrm{uv}}\right)$ for "PT", which is classified into two classes of color according to the results of the hue angle $\left(\mathrm{h}_{\mathrm{uv}}\right)$. Where it was observed that the samples that recorded color angles $\left(\mathrm{h}_{\mathrm{uv}}\right)$ with an average greater than $85^{\circ}$, the color intensity is low compared to the samples of "PT" that recorded the average color angles $\left(\mathrm{h}_{\mathrm{uv}}\right)$ of less than $85^{\circ}$ as described pictorially at Fig. 6.

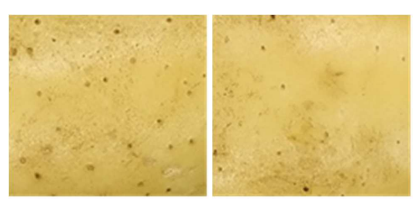

Low-intensity color

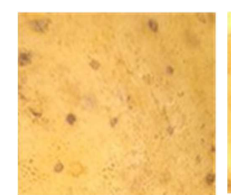

High-intensity color
Fig. 6 Low and high color intensity of some "PT"

\section{Texture analysis}

Texture features of different potato varieties were analyzed by converting the color RGB image into a grayscale image. The gray level co-occurrence matrix (GLCM) is determined using this grayscale image by extracting five texture features, dissimilarity, contrast, entropy, homogeneity, and second moment as listed in Table VI. The average of mean dissimilarity values equals $3.06 \pm$ 0.64 in Alpha against $2.60 \pm 0.73$ in Burn and $1.64 \pm 0.63$ in Spunta. As well, the average value of contrast means observed in Alpha was $20.03 \pm 5.23$ versus $15.55 \pm 5.94$ and $8.70 \pm 4.75$ for Burn and Spunta respectively. It is clear from the results of the texture features analysis by GLCM of "PT", that there were very high values in each of the dissimilarity and contrast versus low values for the homogeneity feature.

TABLE VI

Texture Features Analysis by Grey LeVel Co-OcCurrence Matrix (GLCM) OF "PT"

\begin{tabular}{|c|c|c|c|c|c|c|c|c|c|c|}
\hline \multirow{2}{*}{\multicolumn{2}{|c|}{ Texture features }} & \multicolumn{3}{|c|}{ Alpha } & \multicolumn{3}{|c|}{ Burn } & \multicolumn{3}{|c|}{ Spunta } \\
\hline & & \multirow{2}{*}{$\begin{array}{c}\Sigma \\
3180.83\end{array}$} & \multirow{2}{*}{$\frac{\text { Max. }}{3.70}$} & \multirow{2}{*}{$\frac{\text { Mean }}{0.85}$} & \multirow{2}{*}{$\begin{array}{c}\Sigma \\
3165.36\end{array}$} & \multirow{2}{*}{$\begin{array}{c}\text { Max. } \\
3.08\end{array}$} & \multirow{2}{*}{$\frac{\text { Mean }}{0.75}$} & \multirow{2}{*}{$\begin{array}{c}\Sigma \\
3348.29\end{array}$} & \multirow{2}{*}{$\frac{\text { Max. }}{3.51}$} & \multirow{2}{*}{$\frac{\text { Mean }}{0.90}$} \\
\hline & Min. & & & & & & & & & \\
\hline $\bar{\Xi}$ & Max. & 15287.51 & 7.27 & 4.10 & 62790.75 & 7.70 & 3.98 & 11507.57 & 6.88 & 3.08 \\
\hline छ & Avg. & 11374.34 & 5.94 & 3.05 & 11830.42 & 6.12 & 2.60 & 6134.44 & 5.24 & 1.64 \\
\hline.$\vec{\infty}$ & SD & 2378.00 & 0.87 & 0.64 & 10265.27 & 1.19 & 0.73 & 2356.70 & 1.03 & 0.63 \\
\hline & $\mathrm{CV}$ & 0.21 & 0.15 & 0.21 & 0.87 & 0.19 & 0.28 & 0.38 & 0.20 & 0.38 \\
\hline \multirow{5}{*}{$\begin{array}{c}\overline{\tilde{E}} \\
\stackrel{\Xi}{\Xi} \\
0\end{array}$} & Min. & 40406.04 & 40.28 & 10.83 & 9912.87 & 22.67 & 2.66 & 14057.25 & 30.69 & 3.77 \\
\hline & Max. & 116492.36 & 105.10 & 31.22 & 93481.03 & 106.92 & 25.06 & 75214.40 & 80.87 & 20.16 \\
\hline & Avg. & 74724.10 & 68.59 & 20.03 & 58005.92 & 66.43 & 15.55 & 32446.97 & 53.99 & 8.70 \\
\hline & SD & 19520.04 & 15.37 & 5.23 & 22155.37 & 16.81 & 5.94 & 17721.32 & 15.15 & 4.75 \\
\hline & $\mathrm{CV}$ & 0.26 & 0.22 & 0.26 & 0.38 & 0.25 & 0.38 & 0.55 & 0.28 & 0.55 \\
\hline \multirow{5}{*}{ 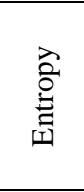 } & Min. & 12382.47 & 4.23 & 3.32 & 8106.43 & 3.79 & 2.17 & 7200.87 & 3.42 & 1.93 \\
\hline & Max. & 15081.94 & 4.37 & 4.04 & 14404.39 & 4.37 & 3.86 & 13702.66 & 4.35 & 3.67 \\
\hline & Avg. & 14072.44 & 4.31 & 3.77 & 12994.04 & 4.26 & 3.48 & 9861.80 & 4.10 & 2.64 \\
\hline & $\mathrm{SD}$ & 741.94 & 0.03 & 0.20 & 1321.95 & 0.11 & 0.35 & 2146.45 & 0.31 & 0.58 \\
\hline & $\mathrm{CV}$ & 0.05 & 0.01 & 0.05 & 0.10 & 0.03 & 0.10 & 0.22 & 0.08 & 0.22 \\
\hline \multirow{5}{*}{ 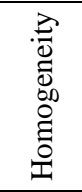 } & Min. & 885.69 & 0.43 & 0.24 & 1039.29 & 0.45 & 0.28 & 1295.22 & 0.69 & 0.35 \\
\hline & Max. & 1577.22 & 0.83 & 0.42 & 2729.99 & 0.97 & 0.73 & 2633.47 & 0.98 & 0.71 \\
\hline & Avg. & 1179.87 & 0.58 & 0.32 & 1429.11 & 0.71 & 0.38 & 2098.86 & 0.90 & 0.56 \\
\hline & SD & 198.89 & 0.11 & 0.05 & 341.67 & 0.13 & 0.09 & 421.35 & 0.09 & 0.11 \\
\hline & $\mathrm{CV}$ & 0.17 & 0.19 & 0.17 & 0.24 & 0.18 & 0.24 & 0.20 & 0.10 & 0.20 \\
\hline \multirow{5}{*}{ 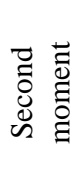 } & Min. & 77.81 & 0.04 & 0.02 & 95.55 & 0.06 & 0.03 & 223.06 & 0.38 & 0.06 \\
\hline & Max. & 358.63 & 0.48 & 0.10 & 741.78 & 0.87 & 0.20 & 1080.89 & 0.91 & 0.29 \\
\hline & Avg. & 124.52 & 0.14 & 0.03 & 191.21 & 0.29 & 0.05 & 702.27 & 0.72 & 0.19 \\
\hline & SD & 57.64 & 0.11 & 0.02 & 123.16 & 0.19 & 0.03 & 343.53 & 0.16 & 0.09 \\
\hline & $\mathrm{CV}$ & 0.46 & 0.77 & 0.46 & 0.64 & 0.68 & 0.64 & 0.49 & 0.23 & 0.49 \\
\hline
\end{tabular}

Comparing these results with its potato images it is observed that there are various shapes of external injuries, which were the cause of the heterogeneity in the tuber surface as shown in Fig. 7.
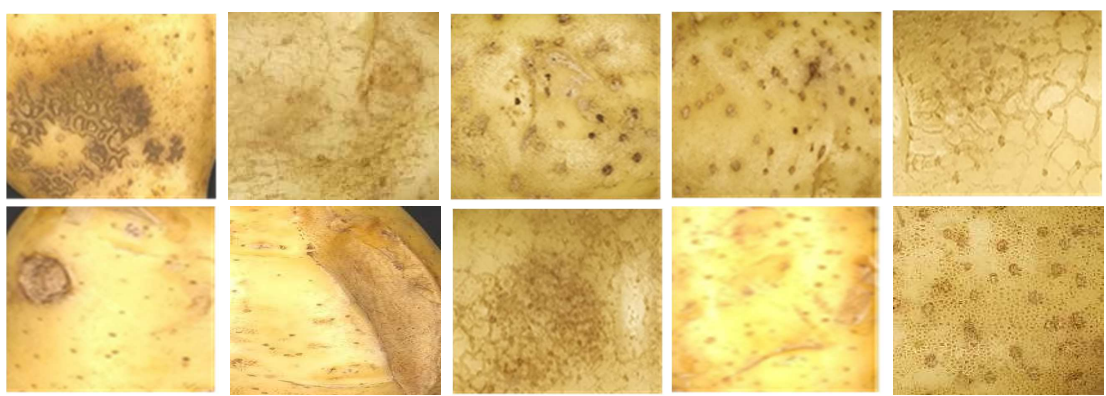

Fig. 7 Depicts some forms of surface injuries on "PT" 
Therefore, it is possible to use these texture features to inspect the "PT" external injuries. The analysis of normality through the Shapiro-Wilk test and the Levene test of the observed factors showed the normality of the values and the homogeneity of the variances, a necessary condition for the ANOVA development variance analysis of the verification of the factors statistically significant in their influence on the results. For the chroma $\left(\mathrm{C}_{\mathrm{uv}}\right)$ color coordinate, tuber size (DIM), and the dissimilarity (GLMC- DISS) the ANOVA showed statistically significant differences between the varieties ( $\mathrm{p}<0.01)$ and between the samples within the three varieties $(\mathrm{p}<0.05)$, while for the other color coordinates there was no significant difference between the means. The analysis of the correlation Table VII, between the values obtained, showed an inverse correlation between the normalized dissimilarity value and the colorimetric coordinates $\mathrm{L}$ and $\mathrm{C}_{\mathrm{uv}}$ of -0.12 , while it showed a positive correlation with the $h_{u v}$ of 0.08 . For the principal component analysis (PCA), factors (DIM), the dissimilarity, contrast, homogeneity from GLMC, and the color coordinates $\mathrm{L}, \mathrm{h}_{\mathrm{uv}}$, and $\mathrm{C}_{\mathrm{uv}}$ were therefore taken into consideration.

TABLE VII

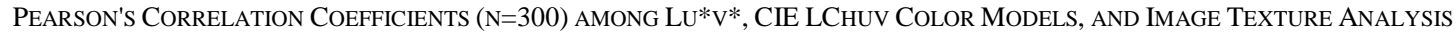

\begin{tabular}{|c|c|c|c|c|c|c|c|c|c|c|c|c|c|c|c|c|}
\hline \multirow[b]{2}{*}{$\mathrm{L}$} & \multicolumn{2}{|c|}{ Dim. Pixels } & \multicolumn{2}{|c|}{$\mathrm{L}$} & \multicolumn{2}{|c|}{$\mathrm{u}^{*}$} & \multicolumn{2}{|c|}{$\mathrm{v}^{*}$} & \multicolumn{2}{|c|}{$\mathrm{h}_{\mathrm{uv}}$} & \multicolumn{2}{|c|}{$\mathrm{C}_{\mathrm{uv}}$} & \multicolumn{2}{|c|}{ Hom. } & \multicolumn{2}{|c|}{ Con. } \\
\hline & $-0,02$ & n.s. & & & & & & & & & & & & & & \\
\hline $\mathrm{u}^{*}$ & 0,41 & $* * *$ & $-0,62$ & $* * *$ & & & & & & & & & & & & \\
\hline $\mathrm{V}^{*}$ & 0,11 & n.s. & 0,21 & $* *$ & 0,05 & n.s. & & & & & & & & & & \\
\hline $\mathrm{h}_{\mathrm{uv}}$ & 0,15 & $*$ & $-0,52$ & $* * *$ & 0,58 & $* * *$ & $-0,25$ & $* * *$ & & & & & & & & \\
\hline $\mathrm{C}_{\mathrm{uv}}$ & 0,13 & n.s. & 0,19 & $* *$ & 0,09 & n.s. & 1,00 & $* * *$ & $-0,25$ & $* * *$ & & & & & & \\
\hline Hom. & 0,23 & $* *$ & 0,25 & $* * *$ & $-0,12$ & n.s. & 0,26 & $* * *$ & $-0,15$ & $*$ & 0,25 & $* * *$ & & & & \\
\hline Con. & $-0,26$ & $* * *$ & $-0,20$ & $* *$ & $-0,12$ & n.s. & $-0,31$ & $* * *$ & $-0,01$ & n.s. & $-0,31$ & $* * *$ & $-0,45$ & $* * *$ & & \\
\hline Dis. & $-0,11$ & n.s. & $-0,12$ & n.s. & $-0,05$ & n.s. & $-0,12$ & n.s. & 0,08 & n.s. & $-0,12$ & n.s. & $-0,14$ & n.s. & 0,17 & $*$ \\
\hline
\end{tabular}

*, **and ${ }^{* * *}$ : significant at $\mathrm{p}<0.05,0.01$ and 0.001 respectively.

$\mathrm{L}$ (Lightness), $\mathrm{u}^{*} \& \mathrm{v}^{*}$ (chromaticity coordinates), $\mathrm{h}_{\mathrm{uv}}$ (hue angle), $\mathrm{C}_{\mathrm{uv}}$ (chroma), DIM=dimension as percentage of total pixels, Hom. (Homogeneity), Con. (Contrast), Dis (Dissimilarity)

The first component PC1 explained $30.76 \%$ of the variance and the second PC2 was $20.86 \%$ of the variance, so overall the biplot of the two components explains almost $51.62 \%$ of the variance and suggests the distribution of the point cloud in three groups (Fig. 8).

The biplot highlights the distribution of points in three groups, which are represented by the ovals that contain $95 \%$., of the samples of each variety. The loadings, that are the coefficients of the linear combination of the initial variables from which the principal components are constructed, that had a greater effect in the distribution of the points on the first component, in a positive way were the homogeneity and the components of the color $\left(\mathrm{L}, \mathrm{C}_{\mathrm{uv}}\right)$ and with a negative effect, the contrast and the color component $h_{u v}$. The loadings that had a greater effect on the distribution of the points on the second component, in a positive way where the component of the color $h_{u v}$ as well the dimension of the tubers, while with a negative effect, the contrast and the color component $\mathrm{L}$. The variables that affect the distribution of the cloud of the points representing the tubers have created a right area of the graph (quadrants I and II) in which the tubers are characterized by greater homogeneity, size (DIM), and higher values of $\mathrm{C}_{\mathrm{uv}}$ and $\mathrm{L}$ color parameters.
Most of the Spunta (rhombus) variety is in this area. On the opposite side of the graph, quadrants III and IV, there are the tubers with greater contrast and dissimilarity texture features, smaller dimensions, and higher $\mathrm{h}_{\mathrm{uv}}$ values.

Most of the Alpha varieties are found in this area, while the Burn variety has about half of the tubers with characteristics like Spunta and the other half more like Alpha variety of the variables observed. The Burn variety had fewer variables values that make up the PCA analysis, because it has low values for both dimensions and colorimetric parameters, in addition to a slightly lower value of texture features. From the texture features values obtained through the GLMC analysis, the verified, with the R software's stats and MASS packages to obtain a prediction model for firmness values of the tubers. The mean square of error (MSE) of the prediction model was 0.47 , the lower among other models, and -49.02 of Akaike information criterion (AIC), was that according to which the: Firmness = $5.35 * * *-0.044$ Contrast* +0.058 Dissimilarity*** -0.006 Homogeneity Where $* * *=$ p-value $<0.001, *=$ p-value $<0.05$ Where this relation between the firmness property of "PT" and texture features extracted from the potato image was verified as tabulated in Table VIII. 

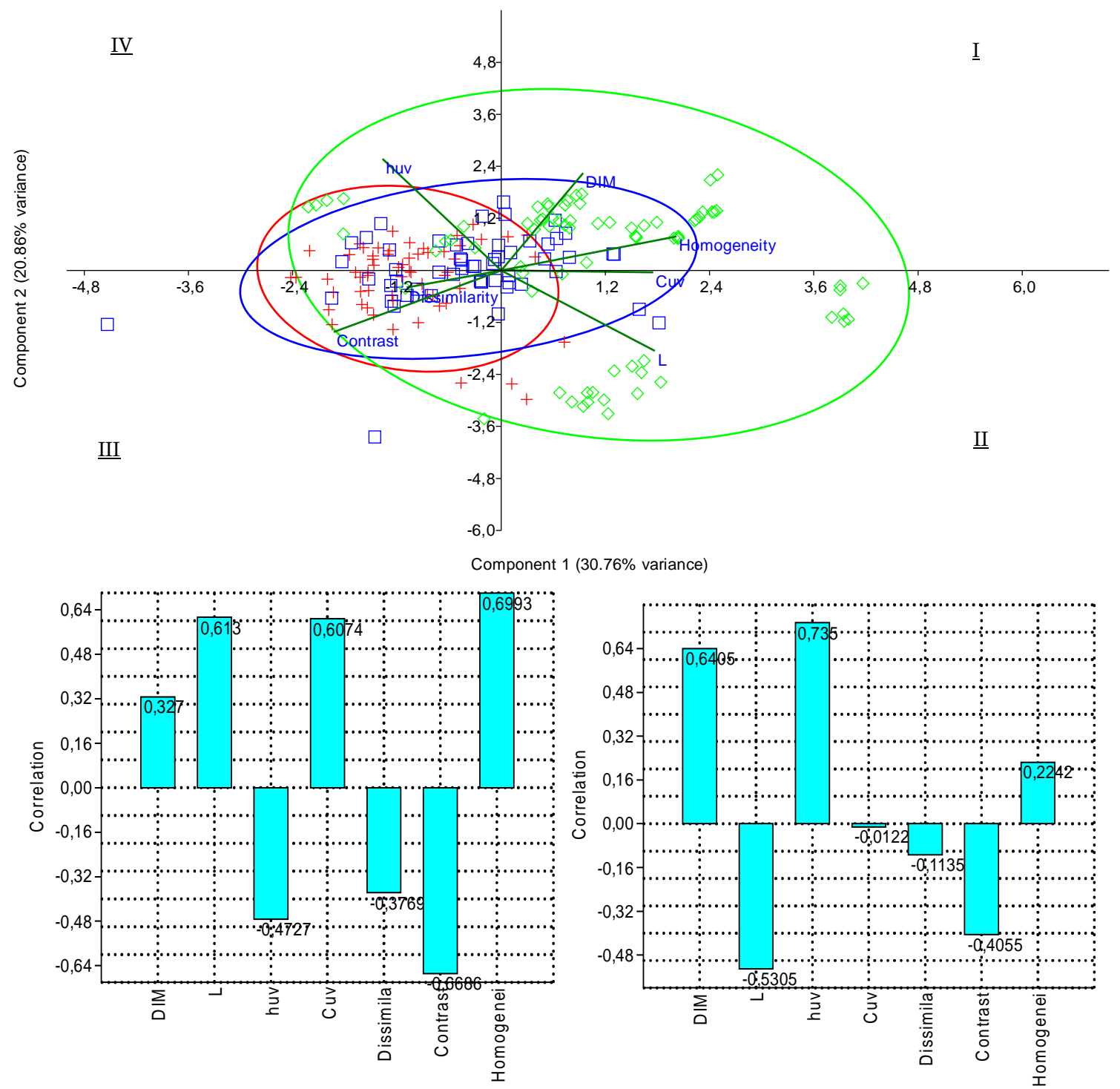

Fig. 8 Score plots of the PCA carried out on DIM, L, $\mathrm{h}_{\mathrm{uv}}, \mathrm{C}_{\mathrm{uv}}$, Dissimilarity, Contrast, and Homogeneity

TABLE VIII

The COMPARISON BETwEen THE MEASURED AND PREDICTED VALUES OF FIRMNESS PROPERTY.

\begin{tabular}{|c|c|c|c|c|}
\hline \multirow{2}{*}{$\begin{array}{c}\text { N. } \\
\text { Samples }\end{array}$} & \multicolumn{4}{|c|}{ Firmness (Kgf) } \\
\cline { 2 - 5 } & $\begin{array}{c}\text { Measured } \\
\text { Value }\end{array}$ & $\begin{array}{c}\text { Predicted } \\
\text { Value }\end{array}$ & $\begin{array}{c}\text { Delta } \\
(\Delta)\end{array}$ & $\begin{array}{c}\text { Error Ratio } \\
(\%)\end{array}$ \\
\hline 1 & 5.20 & 5.68 & 0.48 & 9 \\
\hline 2 & 5.35 & 6.04 & 0.69 & 13 \\
\hline 3 & 5.48 & 5.85 & 0.37 & 7 \\
\hline 4 & 5.59 & 6.43 & 0.84 & 15 \\
\hline 5 & 5.87 & 6.30 & 0.43 & 7 \\
\hline 6 & 6.27 & 6.26 & 0.01 & 0.2 \\
\hline 7 & 6.58 & 6.28 & 0.29 & 4 \\
\hline 8 & 6.82 & 6.26 & 0.56 & 8 \\
\hline 9 & 7.00 & 6.39 & 0.61 & 9 \\
\hline 10 & 7.41 & 6.52 & 0.89 & 12 \\
\hline Average & & & & 8 \\
\hline
\end{tabular}

That clarifies the differences between measured and predicted values of firmness of "PT" and the mean value of the error ratio of about $8 \%$. Through these results, the authors believe that the predictive model of the firmness property needs further study on other varieties of potatoes and more samples to obtain an ideal prediction model for classifying potatoes based on firmness property.

\section{CONCLUSION}

In this study, "AVS" based on "IP" and corresponding algorithms were established and developed by using $\mathrm{R}$ software to inspect the "PT" quality as well as, providing a digital quality index of "PT" depends on mass, color, size grading, and external injuries percentage database. The results showed that the vision system "VS" could inspect the non-destructively external quality of "PT" according to size, mass, color, and texture. Simultaneously, the "VS" proved the potential to determine and classify the color of "PT" into two degrees of deep and light color. The "AVS" was able to measure the texture and to classify the tubers into homogeneous and heterogeneous, i.e., with an external injury. As well, the relationship between the texture features and the firmness property of potatoes needs further study. The results met consumers' needs and the market's requirements by applying good quality criteria, which laid to 
important scientific base for developing a sorting and grading production line of "F\&V" based on an "AVS".

\section{ACKNOWLEDGMENT}

We are grateful to the Science and Technology Development Fund (STDF) where this paper is based upon work supported by (STDF), Egypt, through Short-Term Fellowship (STF- project No. 25329).

\section{REFERENCES}

[1] FAOSTAT., 2016. Production crops, Agricultural production database. http://faostat. fao.org.

[2] MALR., 2018. Ministry of Agriculture and Land Reclamation, Central Administration for Plant Quarantine (CAPQ). Statistical Unit and FAS Cairo office research. GAIN Report Number: EG18026, 115 .

[3] Khojastehnazhand, M., Omid, M., Tabatabaeefar, A., 2010. Determination of tangerine volume using image processing methods. Int. J. Food Prop. 13 (4), 760-770.

[4] Naik, S., Patel, B., 2017. Machine vision-based fruit classification and grading-A review. Int. J. Comput. Appl. 170 (9), 22-34.

[5] Arendse, E., Fawole, O.A., Magwaza, L.S., Opara, U.L., 2018. Nondestructive prediction of internal and external quality attributes of fruit with thick rind: A review. J. Food Eng. 217, 11-23.

[6] Satpute, M.R., Jagdale, S., 2016. Color, size, volume, shape and texture feature extraction techniques for fruits: A review. Int. Res. J. Eng. Technol. 3, 703-708.

[7] Pu, Y.Y., Feng, Y.Z., Sun, D.W., 2015. Recent progress of hyperspectral imaging on quality and safety inspection of fruits and vegetables: A review. Comprehensive Reviews in Food Science and Food Safety 14, 176-188.

[8] Ehsani, R., Toudeshki, A., Wan, P.J.T.P., 2016. New sensor technology for yield estimation and disease detection. Tomato Proceedings, 15-16.

[9] Karlsson, P., 2016. Is Manual Harvest Really Better Than Mechanical Harvest? Retrieved from https://www.bkwine.com/features/ winemaking-viticulture/raw-truthmanualmechanical-harvest/.

[10] Chen, Y.R., Chao, K., Kim, M.S., 2002. Machine vision technology for agricultural applications. Comput. Electron. Agric. 36, 173-191.

[11] Moreda, G.P., Muñoz, M.A., Ruiz-Altisent, V., Perdigones, A., 2012. Shape determination of horticultural produce using two-dimensional computer vision - A review. Journal of Food Engineering 108 (2), 245-261.

[12] Nyalala, I., Okinda, C., Nyalala, L., Makange, N., Chao, Q., Chao, L., Yousaf, K., Chen, K., 2019. Tomato volume and mass estimation using computer vision and machine learning algorithms: Cherry tomato model. Journal of Food Engineering 263, 288-298.

[13] Ibrahim, A.A., Eisa, A.H., Alghannam, A.O., 2014. Image processing system for automated classification date fruit. International Journal of Advanced Research 2(1), 702-715.

[14] Jadhav, T., Singh, K., Abhyankar, A.J.M.T., 2019. Volumetric Estimation Using 3D Reconstruction Method for Grading of Fruits. Multimedia Tools and Applications 78, 1613-1634.
[15] Shafiee, S., Minaei, S., Moghaddam-Charkari, N., Barzegar, M., 2014. Honey characterization using computer vision system and artificial neural networks. Food Chem. 159, 143-150.

[16] Arjenaki, O.O., Moghaddam, P.A., Motlagh, A.M., 2013. Online tomato sorting based on shape, maturity, size, and surface defects using machine vision. Turk. J. Agric. For. 37, 62-68.

[17] Noordam, J.C., Otten, G.W., Timmermans, A.J.M., Zwol, B., 2000 High-speed potato grading and quality inspection based on a color vision system. In: Proceeding of SPIE - Machine Vision Application in Industrial Inspection, 206-217.

[18] Halimi, A., Roukhe, A., Abdenabi, B., El Barbri, N., 2013. Sorting dates fruit bunches based on their maturity using camera sensor system. Journal of Theoretical and Applied Information Technology 56(2).

[19] Moallem, P., Serajoddin, A., Pourghassem, H., 2017. Computer vision-based apple grading for golden delicious apples based on surface features. Inf. Process. Agric. 4 (1), 33-40.

[20] Tian, D. P., 2013. A review on image feature extraction and representation techniques. International Journal of Multimedia and Ubiquitous Engineering 8, 385-396.

[21] Haralick, R.M., 1979. Statistical and Structural Approaches to Texture. Proceeding of the IEEE 67, 786-804.

[22] Mathworks Inc., 2013. Matlab's Statistic Toolbox 7. Natick, MA: Mathworks Inc., Matlab.

[23] Fongaro, L., Kvaal, K., 2013. Surface texture characterization of an Italian pasta by means of univariate and multivariate feature extraction from their texture images. Food Res. Int. 51, 693-705.

[24] Ireri, D., Belal, E., Okinda, C., Makange, N., Ji, C., 2019. A computer vision system for defect discrimination and grading in tomatoes using machine learning and image processing. Artificial Intelligence in Agriculture 2, 28-37.

[25] Baigvand, M., Banakar, A., Minaei, S., Khodaei, J., BehrooziKhazaei, N., 2015. Machine vision system for grading of dried figs. Computers and Electronics in Agriculture 119, 158-165.

[26] Weijun, X., Wang, F., Yang, D., 2019. Research on Carrot Grading Based on Machine Vision Feature Parameters. IFAC PapersOnLine 52(30), 30-35.

[27] ElMasry, G., Cubero, S., Moltó, E., Blasco, J., 2012. In-line sorting of irregular potatoes by using automated computer-based machine vision system. Journal of Food Engineering 112, 60-68.

[28] Al-Mallahi, A., Kataoka, T., Okamoto, H., and Shibata, Y., 2010. An image processing algorithm for detecting in-line potato tubers without singulation. Computers and Electronics in Agriculture 70, 239-244.

[29] Mohsenin, N.N., 1986. Physical Properties of Plant and Animal Materials, Gordon and Breach Science Publishers, New York, USA.

[30] R Core Team., 2019. R: A language and environment for statistical computing. R Foundation for Statistical Computing, Vienna, Austria. URL https://www.R-project.org/.

[31] Poynton, C., 2003. Digital Video and HDTV. Morgan-Kaufmann. p. 226. ISBN 1-55860-792-7.

[32] Handcock, M.S., Chaudhuri, S., Rendall, M.S., 2004. glmc: An R package for generalized linear models subject to constraints. http://www.stat.washington.edu/handcock/combining. 